\title{
Cost Calculation in Research and Development of New Validation Methods
}

\author{
Alexandra ZAHORSKA, Simona MUNZAROVA* and Jana KOSTALOVA \\ 1 University of Pardubice, Pardubice, Czech Republic; alexandra.zahorska@student.upce.cz; \\ simona.munzarova@upce.cz; jana.kostalova@upce.cz \\ * Corresponding author: simona.munzarova@upce.cz
}

\begin{abstract}
In this paper, we focus our attention primarily on management tools and techniques that could be applied in the pre-production stage of the production process, respectively in the $R \& D$ stage. Attention is focused on Strategic cost management and its tools in $R \& D$. Innovations and $R \& D$ are necessary for business to build competitive advantage, but looking closer at R\&D activities, we could see constantly increasing costs, the costs of professional staff, instrumentation, aids, etc. So, it is appropriate to find and apply proper management methods, tools and techniques of strategic cost management. This article is based on the results of research dealing with the cost analysis of a newly developed method for the toxicity testing of nanomaterials. For the purposes of analysis and cost calculation, one of the newly developed validation methods for determining the toxicity of nanomaterials was selected. In the conditions of laboratory research, it was found that mainly activities are the main cost object for cost calculations. It seems advantageous to use the Activity Based Costing method for managing or determining the costs at $R \& D$ laboratories or for cost calculations of the newly developed methods.
\end{abstract}

Keywords: costing; R\&D activities; testing; nanomaterials; activity-based costing

JEL Classification: O32; O31

\section{Introduction}

Management and improvement of R\&D is a continuous process that requires utilization of many strategic management practice, considering the specific nature of $R \& D$ costs. In today's world of economic change, globalization, digitization, or the threat of climate change, companies must make increasing efforts to adapt to continuous changes in the business environment, keep pace with rapidly changing market conditions, innovate their processes, adopt new concepts. The growing complexity of technologies, the rising costs of product innovations, including uncertainty in their development and implementation, require strong management tools and procedures. Strategy's success requires to apply suitable strategy tools that help managers to decide, at all the stages of strategic management, to improve processes and increase overall business performance. (Nouri et al., 2017; Qehaja et al., 2017; Tetrevova, 2004). The results of the survey in several studies that analyzed the tools and techniques of strategic management indicated that it is necessary to continue to pay attention to their implementation in companies, their development and understanding. (Afonina et al., 2013; Bingöl et al., 2017; Clark, 1997) 
When making strategic decisions about the actual implementation of research and development, long-term investments, purchases of services or products, or their own implementation, etc., it is necessary to have appropriate tools and techniques of strategic management accounting SCM (Berisha, 2017; El-Dyasty, 2007). Focus on optimization of the costs for future processes in the pre-production stages during investment decision-making phase can help create a solid foundation for these processes, which will not be subject to additional significant changes. At present, however, there is no comprehensive register of tools and techniques of strategic cost management in the literature. Following 10 tools and techniques of strategic cost management have appeared in literature with a higher frequency: Activity based costing, Balanced scorecard, Benchmarking, Competitor cost assessment, Customer accounting, Life cycle costing, Strategic costing, Strategic pricing, Target costing, Value based costing.

In the area of $R \& D$ cost management, the lack of use of economic management tools can be encountered, as Shields (1994) explained in the past by saying, "The creativity of scientists and technicians working in R\&D laboratories should not be limited by cost concerns." The costs of R\&D activities are constantly increasing, the costs of professional staff, instrumentation, aids, etc. are increasing. Thus, the application of new methods and tools of strategic cost management may be appropriate. It is necessary to study the R\&D cost management environment and select appropriate procedures and tools and implement appropriate changes. Such a change was the application of the process approach to activity management, the implementation of the Activity Based Costing (ABC) method. The basic idea of this method is cost management based on cost relationship to activities as basic cost objects, which distinguishes ABC from traditional costing systems (Oseifuah, 2014). The starting point of the $\mathrm{ABC}$ method are three key assumptions: it is necessary to use activities to create products, activities consume resources, resources require money. This new approach for performing cost calculations has contributed to solving the problem of everincreasing overhead costs for product production, which is mainly due to the strengthening of the production automation process in organizations and also more complex production processes (Almeida et al., 2017). ABC procedures as a suitable cost management tool could be also beneficial to use in laboratories, including laboratory research. McDowell (2005) examines the use of the $\mathrm{ABC}$ method for calculation of costs in hospital laboratories, looking for ways to remedy the ever-burdensome budget of laboratories, caused primarily by the increasing volume of tests and, as a result, the increasing need for persons. She described the calculation of costs using the $\mathrm{ABC}$ method as a suitable tool for cost management in laboratories and finding the optimal variant of the cost budget of these laboratories

Newly, also Hajighasemi and Azhdari (2020) suggests that the time driven model of Activity based costing reports better the cost of services. On the other hand, Price et al. (2020) discuss that in case of healthcare, $A B C$ should move towards value-based approach paying attention also to its stakeholders.

Another tool and technique of strategic cost management for the calculation of research laboratory costs is Life cycle costing (LCC). One of the basic features of LCC is the evaluation of not only the costs of the production stage of the product, but its entire life cycle, the so-called gradle to grave (Knauer \& Möslang, 2018). According to Lindholm and Suomala (2002), this method requires 
a large amount of diverse hard-to-reach data, complicated calculations and long-term predictions. Kambanou (2020) and Olubodun (2010) also mention the deficit in demand for LCC technology, the lack of a standardized methodology, etc. On the contrary, according to Knauer and Möslang (2018), the LCC technique is an adequate strategic tool for organizations. It helps to determine the organization's cost of a product or service and to understand the behavior of individual cost elements at different stages of the life cycle (Lindholm \& Suomala, 2002).

The development of new drugs and similarly nanomaterials is a highly innovative sector. Empirical analyzes of R\&D costs are interesting at least for analyzes of return on investment in research and development, in the case of a new drug they affect the structure of innovation in pharmaceutical products. Many studies in biomedicine and drug testing deal with cost requirements or other economic analyzes. Following studies can be mentioned as an example: Simeons et al. (2017) deals with the role of budget impact analysis when assessing biosimilars, Moore et al. (2018) points out, based on a cost analysis of Pivotal Trials for Novel Therapeutic Agents Approved by the US Food and Drug Administration, that costs increase with the increasing number of patients enrolled in trials, or in connection with the need to prove that a new drug has the same or better clinical benefit than any other, already available drug . DiMasi et al. (2003) deals with investment cost for new drug development. Rovida and Hartung (2009) discuss costs for in vivo tests to accomplish REACH legislation pointing that it is the largest investment into consumer product safety ever. Prasad and Mailankody (2017) deal with cost of R\&D to get a drug, particularly 10 cancer drugs, to Market and compares it with Revenues After its Approval.

Nanotechnology can currently be described as one of the highly innovative technologies of the 21st century, also due to its use in R\&D activities, where it is considered to be extremely beneficial, especially when it comes to biotechnology, medical and pharmaceutical disciplines. This researched field can provide many solutions to unresolved issues related to the medical flied, especially in the prevention, diagnosis but also the treatment of various diseases. (Leso 2019) At present, many authors have appeared, who in their contributions deal with the issue of the use of nanomaterials in medical practice. One of them is Boisseau and Loubaton (2011), as well as Kubinova and Sykova (2010), who deal with the use of nanotechnology in regenerative medicine, where they point to the application of nanomaterials in tissue engineering and cell therapy as a modern approach in disease therapy. In this area, nanomaterials can support cell growth and thus provide stimulation and subsequent regeneration of damaged tissues and organs. Nyström and Fadeel (2012) highlights nanotechnology as an exceptional opportunity for target drug delivery, where the efficacy of a drug at a target site may be improved by reducing its dose in surrounding tissues and thereby reducing its side effects. Fakruddin (2012) investigates further medical uses of nanomaterials, and points in particular to diagnostic applications, such as nucleic acid diagnostics, which allows the detection of damaged cells in the earlier stages of various diseases. It also draws attention to the application of nanomaterials as target probes and imaging instruments, but also to therapeutic applications of nanomaterials, such as their use in biomolecular engineering, biopharmaceuticals, cardiotherapy, dental treatment but also in the orthopedic sphere. One of the many other applications of nanomaterials in medicine is 
also addressed by Kargozar and Mozarafi (2018), specifically the use of nanotechnology as a therapeutic tool, especially in the treatment of various cancers, where in many respects, nanotechnology is considered a more effective strategy in cancer therapy than conventional chemotherapeutics. Barkalina et al. (2014), on the other hand, emphasize the current growing trend in applications such as the use of nanomaterials in reproductive biology and medicine. The discovery of new nanomaterials and their applications also raises questions related to safety and sustainability.

However, there are currently limited data on the toxicity of nanomaterials and their behavior in the biological systems. At present, the main challenge for nanotoxicological processes is to analyze the significant difference in reported toxicity studies. Furthermore, it is also appropriate to assess the costs not only for the development and production of the product, but also for its evaluation / verification. The aim of this article is to evaluate the use of current methods and possibilities of using cost accounting procedures in the field of R\&D and based on the results of research to present and discuss possible procedures for determining the costs of selected newly developed method for determining the toxicity of new nanomaterials.

\section{Methodology}

Primary qualitative research was carried out to identify current cost management practices and to determine the costs of R\&D activities in a research facility dealing with the development of toxicity testing methods for newly developed nanomaterials.

First part of the research, the identification of current cost management practices, was carried out by the method of individual interviews with the managers of the relevant project and with a senior researcher who develops procedures for determining the toxicity of nanomaterials. The second part of the research was an in-depth analysis of individual types of costs and time frames of individual activities of pre-selected methods for determining the toxicity of nanomaterials, developed at the workplace. This part of the research was carried out both by separate measurements and by expert estimates of the main researcher. The sequence of steps was monitored for each individual method. In each of them, an in-depth analysis of costs, time, consumables, capital equipment, researchers, etc. was performed. Four testing methods were selected for the research, while an in-depth analysis was performed for two of these methods. Based on information on the costs and time required for specific testing toxicity methods a calculation of their costs was compiled. The analysis also included an evaluation of the proposed changes in the cost management system in case of modified usage of instruments by more validation methods and different type of depreciation.

\section{Results}

\subsection{Characteristics and Structure of Project and Laboratory Expenses}

Research of the costs and time consumption for developed methods was part of a research project for which a team of scientific experts was assembled and a special research infrastructure was created to develop and characterize new nanomaterials, modify them and 
test the impact of these newly developed nanomaterials on the human body. The process of testing the toxicity of nanomaterials is very time-consuming, professionally and financially demanding. The key goal of the project is to create a multi-departmental center consisting of several top research institutes. Each workplace works with its own budget, so it was possible to compare the cost structure for the project at given workplace and for laboratory research of the workplace, where the project was realized.

Based on the analysis of project expenses in planned project budget and laboratory costs, these expenses were divided into six groups. The total value of individual expenses groups differs from each other and in the case of a project may be significantly affected by the requirements of the grant provider for the project. The following table 1 provides ascending expenses groups from the highest percentage items to the lowest expenditure items broken down by project and laboratory.

Table 1. Structure of project expenses and expenses in research laboratory department

\begin{tabular}{|c|c|c|}
\hline Type of Expense & Project & Laboratories \\
\hline Personal exp. & $41.6 \%$ & $32 \%$ \\
\hline Investments & $28 \%$ & $31 \%$ \\
\hline Operation exp. of research & $15.1 \%$ & $15 \%$ \\
\hline Services & $6 \%$ & $6.3 \%$ \\
\hline Travelling exp. & $5.9 \%$ & $9.2 \%$ \\
\hline Administration overhead & $3.8 \%$ & $6.5 \%$ \\
\hline
\end{tabular}

Personnel expenses represent the most expensive item in the total budget. This category of expenses also includes social and health insurance and other statutory insurance. The salaries of researchers are set with regard to their qualifications. Capital expenses are related to the purchase of new laboratory equipment. The operating expenses for the implementation of research include mainly chemicals, biomaterials, small laboratory equipment, protective equipment, consumables, etc. Services and travel costs are equally demanding on the budget. Services include, in particular, instrument repairs, publication costs, outsourcing of special analyzes and costs of intellectual property protection. Travel expenses cover the participation of researchers in various professional conferences in the Czech Republic and abroad, internships to train researchers in working on new devices, trade fairs and innovation and investor forums to present research results and to establish partnerships. The last and lowest item is administrative expenses.

As it is possible to see the structure of expenses in terms of the whole project and also the department, resp. laboratory where the validation method is developed, is very similar in terms of percentage comparison. A smaller share of expenses in the monitored department compared to expenses for the entire project is represented by personal expenses, indicating the participation of experts with higher qualifications. Furthermore, it is possible to see higher capital expenses within the monitored department, which, however, can also be used for the project. At the same time, the department has a higher percentage for travel and administrative expenses. 


\subsection{Cost Analysis of Selected Developed Methods for Determining the Toxicity of Nanomaterials}

The toxicity of nanomaterials could be assessed by various methods. Our final cost analysis focused on two key methods, which can be described as:

1. Setting method, which allows to find out the parameters for the second, routine analysis. One type of nanomaterial is tested by this method in a smaller number of concentrations and repetitions.

2. The routine method evaluates the possible toxicity of the tested nanomaterial. The testing process takes place in multiple concentrations, with more replicates and more cell incubations.

To analyze the possibilities of compiling a cost calculation, the costs were first divided into direct and indirect to the implemented methods of toxicity testing of nanomaterials. The direct costs were some laboratory supplies and materials. However, the cost analysis revealed that some laboratory aids and materials are used at the same time by several methods, several methods involve the same differently qualified laboratory technicians and researchers, different methods and their partial activities use some of the same instruments, in the same rooms, similarly, a number of items of small assets are consumed by several methods, i.e. these are indirect costs. Direct costs accounted for only about $12 \%$ of total costs. To calculate the indirect costs, the causal relationship between the expenditure of these costs and the implementation of the given method of testing the toxicity of nanomaterials was analyzed, in order to determine the appropriate scheduling basis. This analysis showed that the reason for these costs is the repetitive activities that make up the various methods for determining toxicity. At the same time, the relationship between individual activities and the volume of performed methods for testing the toxicity of nanomaterials was analyzed in order to complete the cost calculation.

The obtained data were determined for individual phases of the experiment, structured into individual laboratory activities, further according to persons and their qualifications, working time, and similarly for devices. The type of consumables and chemicals for each activity and their purchase price were determined.

Both above mentioned methods for determining the toxicity of nanomaterials differ in the number of concentrations of the analyzed sample, or in the number of repetitions of the experiment, but both methods are same in the four basic phases of testing that the experiment goes through. These are: the phase of preparation of nanomaterials, the phase of preparation of cells, the phase of incubation of cells with nanomaterials and the phase of determining the toxicity of nanomaterials. These phases again differ in the complexity of the individual steps (activities) in terms of time consumed, the place to perform the experiments, the relevant staff and instrumentation, as well as the necessary consumables and other materials. But again, as both methods are same in their phases, they are also same in activities within these phases, activities differ by number of iterations and time consumption, as indicated in the following Table 2, which shows part of the data obtained. 
Table 2. Example of data sheet on time consumption by each activity in both testing methods

\begin{tabular}{|c|c|c|c|c|c|}
\hline \multirow[b]{2}{*}{ Phase } & \multirow[b]{2}{*}{ Activity } & \multicolumn{2}{|c|}{ Method 1} & \multicolumn{2}{|c|}{ Method 2} \\
\hline & & $\begin{array}{c}\text { Time person } \\
\text { (min) }\end{array}$ & $\begin{array}{c}\text { Time equip. } \\
\text { (min) }\end{array}$ & $\begin{array}{c}\text { Time person } \\
\text { (min) }\end{array}$ & $\begin{array}{c}\text { Time equip. } \\
\text { (min) }\end{array}$ \\
\hline \multirow{3}{*}{$\begin{array}{l}\text { Experiment } \\
\text { preparation }\end{array}$} & $\mathrm{a}$ & 10 & 10 & 10 & 10 \\
\hline & $\mathrm{b}$ & 10 & 35 & 10 & 35 \\
\hline & $\mathrm{c}$ & 15 & 5 & 20 & 10 \\
\hline \multirow{4}{*}{ Cells preparation } & $\mathrm{d}$ & 80 & infinite & 80 & infinite \\
\hline & $\mathrm{e}$ & 20 & 30 & 20 & 30 \\
\hline & $\mathrm{f}$ & 1,080 & 1,080 & 1,800 & 1,800 \\
\hline & $\mathrm{g}$ & 60 & 0 & 120 & 0 \\
\hline \multirow{3}{*}{$\begin{array}{l}\text { Incubation (NM } \\
\text { with cells) }\end{array}$} & $\mathrm{h}$ & 120 & 120 & 1,080 & 1,080 \\
\hline & $\mathrm{i}$ & 30 & 30 & 270 & 270 \\
\hline & $\mathrm{j}$ & 10 & 1,440 & 90 & 12,960 \\
\hline \multirow{3}{*}{$\begin{array}{l}\text { Toxicity of NM } \\
\text { determination }\end{array}$} & $\mathrm{k}$ & 10 & 10 & 90 & 90 \\
\hline & 1 & 5 & 60 & 45 & 540 \\
\hline & $\mathrm{m}$ & 120 & 0 & 540 & 0 \\
\hline
\end{tabular}

Based on the obtained information, a cost calculation of the developed method for testing the toxicity of nanomaterials was compiled. First, the traditional way of determining costs on each method was performed. As the analysis showed that the objects that cause costs are mainly individual activities and number of these activities are repeated in the laboratory, or differ only in time consumption or number of repetitions, it could be useful to compile a cost calculation using the Activity Based Costing.

Furthermore, number of costs analyzes was performed, considering other factors, such as the inclusion of other methods for determining the toxicity of nanomaterials and thus bringing better use of laboratory capacity, or tax depreciation was changed to accounting depreciation, etc. These factors affect the total cost in the final cost calculation for these methods. The following Table 3 summarizes the influence of some factors on the total cost of the developed method for determining the toxicity of nanomaterials.

Table 3. Total cost of analyzed method under different factors

\begin{tabular}{|c|c|c|c|c|}
\hline & $\begin{array}{c}\text { Without time } \\
\text { use }\end{array}$ & $\begin{array}{c}\text { Time use considered, } \\
\text { tax deprec. }\end{array}$ & $\begin{array}{c}\text { Accounting deprec. } \\
\text { (twice longer) }\end{array}$ & $\begin{array}{c}\text { Instruments used by 4 } \\
\text { methods, tax deprec. }\end{array}$ \\
\hline $\begin{array}{c}\text { Lab. material and } \\
\text { equipment }\end{array}$ & $13 \%$ & $16 \%$ & $16 \%$ & $18 \%$ \\
\hline Wages & $46 \%$ & $60 \%$ & $58 \%$ & $67 \%$ \\
\hline Research instruments & $42 \%$ & $23 \%$ & $26 \%$ & $15 \%$ \\
\hline Total cost (CZK) & 24,118 & 18,353 & 19,049 & 16,591 \\
\hline
\end{tabular}

The resulting total cost of the method varies by up to approximately $35 \%$. These calculations differ in how the depreciation of the instruments was assigned to the method. The second column allocates the cost only between the two methods analyzed, which would make sense if only these two methods were implemented in the laboratory. The third column 
works with the time use of instruments based on the results of the analysis of activities and essentially corresponds to the procedures of Time Driven Activity Based Costing. The fourth column takes into account the possibility of using the devices for twice as long as is set aside for tax depreciation, which better corresponds to the actual use of the devices in practice. The fifth column retains the original depreciation, but calculates it equally among the several methods that are implemented on the same devices.

\section{Discussion}

In order to clarify the cost calculation of the observed toxicity testing method, some factors were included in the discussion:

1. The calculation of the test method included the actual time of use of selected instruments obtained from the time analysis. Especially for new instruments that are purchased under the project for the analysis of these methods, they are not fully utilized but they have the potential to be used for further laboratory analyzes in the future. This may reduce the cost of the method, but provide, that we plan to use the instrument for further analysis.

2. The calculation of the test method considered the estimated actual length of use of the instruments compared to the one used for depreciation of these instruments. It was necessary to consult this fact with researches, who uses the instruments.

3. The calculations were verified on the basis of cost analysis that include implementation of other testing methods. It was confirmed that the objectives of costs are mainly activities. These can be both repeated for individual developed methods and also be specific to the given method, however, these are again also repeated in one method.

4. Activities are a relevant cost object not only for depreciation of equipment, but also in terms of consumption of other assets or labor costs, etc. Although their calculation has not been shown here, they can be approached again according to the principles of Activity Based Costing.

For future research, it could be interesting to bring more studies on best practices of managing research and development costs, to find appropriate procedures and tools. None of these could be processed only by cost managers, thee important role plays the discussion with researches that know the environment of R\&D laboratories. Both for new nanomaterials and their use in biomedicine, as well as for new toxicity testing methods, markets are just beginning to emerge. Then, for example, Target Costing or value-based procedures could also be used. In the research and development phase, cost calculation using the LCC method can be considered, but for its data it would first be appropriate to process sustainability LCA.

\section{Conclusion}

This article focuses on the cost analysis of a newly developed method for testing the toxicity of nanomaterials. Analyzes were performed on newly developed validation methods for determining the toxicity of nanomaterials. In the conditions of laboratory research, it was found that the main cost object for cost calculation are mainly activities. The individual activities are repeated in some phases of the experiment and at the same time these activities also appear in other developed methods of testing the toxicity of nanomaterials within the 
given project. It was therefore proposed to use cost-based costing procedures for cost allocation. For further analysis, it is worth using its modification, which is Time Driven Activity Based Costing, due to a number of repetitive steps that are equally demanding, for example, on the equipment used or human labor. We thus consider the Activity Based Costing and Management method to be an important tool for cost management in the environment of R\&D laboratories, which currently use budgets primarily as cost management tools.

Acknowledgments: This work was supported by OP RDE project „Strengthening interdisciplinary cooperation in research of nanomaterials and their effects on living organisms“, reg. n. CZ.02.1.01/0.0/0.0/17_048/0007421.

\section{References}

Afonina, A., \& Chalupsky, V. (2013). Investigation of strategic management tools and techniques. Acta Universitatis Agriculturae et Silviculturae Mendelianae Brunensis, 61(4), 833-840. https://doi.org/10.11118/actaun201361040833

Almeida, A., \& Cunha, J. (2017). The implementation of an Activity-Based Costing (ABC) system in a manufacturing company. Procedia Manufacturing, 13, 932-939. https://doi.org/10.1016/j.promfg.2017.09.162

Barkalina, N., Charalambous, Ch., Jones, C., \& Coward, K. (2014). Nanotechnology in reproductive medicine: Emerging applications of nanomaterials. Nanomedicine: nanotechnology, biology, and medicine, 10(5), 921-938. https://doi.org/10.1016/j.nano.2014.01.001

Berisha, V. (2017). Strategic Management of Costs: A New Tool to Gain Competitive Advantage. In N. Tsounis, \& A. Vlachvei (Eds.) Advances in Applied Economic Research (pp. 239-254) Springer Proceedings in Business and Economics. https://doi.org/10.1007/978-3-319-48454-9_17

Bingöl, D., Filizöz, B., Okan, T., \& Çapkulaç, O. (2017). The Effect of The Strategic Management Tools on SMEs' Firm Performance. The European Proceedings of Social \& Behavioural Sciences -13th International Strategic Management Conference 2017 (pp. 352-362). https://doi.org/10.15405/epsbs.2017.12.02.30

Boisseau, P., \& Loubaton, B. (2011). Nanomedicine, Nanotechnology in medicine. Comptes Rendus Physique, 12(7), 620-636. https://doi.org/10.1016/j.crhy.2011.06.001

Carlin, B. I. (2009). Strategic price complexity in retail financial markets. Journal of Financial Economics, 91(3), 278287. https://doi.org/10.1016/j.jfineco.2008.05.002

Clark, D. (1997). Strategic management tool usage: a comparative study. Strategic Change, 6, 417-427. https://doi.org/10.1002/(SICI)1099-1697(199711)6:7\%3C417::AID-JSC281\%3E3.0.CO;2-9

DiMasi, J. A., Hansen, R. W, \& Grabowski, H. G. (2003). The price of innovation: new estimates of drug development costs. Journal of Health Economics, 22(2), 151-185. https://doi.org/10.1016/S0167-6296(02)00126-1

El-Dyasty, M. M. (2007). A Framework to Accomplish Strategic Cost Management. SSRN Electronic Journal, 2-6. https://doi.org/10.2139/ssrn.704201

Fakruddin, M. H. Z., \& Afroz, H. (2012) Prospects and applications of nanobiotechnology: a medical perspective. J Nanobiotechnol, 10(31), 1-8. https://doi.org/10.1186/1477-3155-10-31

Hajighasemi, M., \& Azhdari, M. (2020). Comparative Examination of the Treatment Costs of Pediatric Digestion Patients Using Time-Driven Activity-Based Costing and Traditional Models (Case Study: Shahid Sadoughi Hospital, Yazd). Journal of Accounting Research, 10(3), 135-156. https://doi.org/10.22051/ijar.2020.27016.1523

Kambanou, M. L. (2020). Life Cycle Costing: Understanding How It Is Practised and Its Relationship to Life Cycle Management - A Case Study. Sustainability, 12(8), 3. https://doi.org/10.3390/su12083252

Kargozar, S., \& Mozafari, M. (2018). Nanotechnology and Nanomedicine: Start small, think big. MaterialsToday: Proceedings, 5(7), 15492-15500. https://doi.org/10.1016/j.matpr.2018.04.155

Knauer, T., \& Möslang, K. (2018). The adoption and benefits of life cycle costing. Journal of Accounting $\mathcal{E}$ Organizational Change, 14(2), 188-215. https://doi.org/10.1108/JAOC-04-2016-0027

Kubinova, S., \& Sykova, E. (2010). Nanotechnologies in regenerative medicine. Minimally invasive therapy, 19(3), 144-156. https://doi.org/10.3109/13645706.2010.481398

Leso, V., Fontana, L., \& Iavicoli, I. (2019). Biomedical nanotechnology: Occupational views. Nano Today, 24, 10-14. https://doi.org/10.1016/j.nantod.2018.11.002 
Lindholm, A., \& Suomala, P. (2002). Present and future of life cycle costing: reflections from Finnish companies. Liiketaloudellinen Aikakauskirja, 282-292.

López-Robles, J. R., Rodríguez-Salvador, M., Gamboa-Rosales, N. K., Ramirez-Rosales, S., \& Cobo, M. J. (2019). The last five years of Big Data Research in Economics, Econometrics and Finance: Identification and conceptual analysis. Procedia Computer Science, 162, 729-736. https://doi.org/10.1016/j.procs.2019.12.044

McDowell, J. (2005). Using Activity-Based Costing to Aid in the Selection of Laboratory Equipment. Laboratory medicine, 36(5), 278-280. https://doi.org/10.1309/5P8UFDCL9E04WP20

Moore, T. J., Zhang, H., Anderson, G. \& et al (2018). Estimated Costs of Pivotal Trials for Novel Therapeutic Agents Approved by the US Food and Drug Administration, 2015-2016. JAMA Intern Med., 178(11), 14511457. https://doi.org/10.1001/jamainternmed.2018.3931

Nouri, B.A., \& Soltani, M. (2017). Analyzing the Use of Strategic Management Tools and Techniques between Iranian Firms. Academy of Strategic Management Journal, 16(1), 263-272.

Nyström, A., \& Fadeel, B. (2012). Safety assessment of nanomaterials: Implications for nanomedicine. Journal of controlled release, 161(2), 403-408. https://doi.org/10.1016/j.jconrel.2012.01.027

Olubodun, F., Kangwa, J., Oladapo, A., \& Thompson, J. (2010). An appraisal of the level of application of life cycle costing within the construction industry in the UK. Structural Survey, 28(4), 254-265. https://doi.org/10.1108/02630801011070966

Oseifuah, E. (2014). Activity based costing (ABC) in the public sector: Benefits and challenges. Problems and Perspectives in Management, 12(4), 581-588.

Prasad V., \& Mailankody S. (2017). Research and Development Spending to Bring a Single Cancer Drug to Market and Revenues After Approval. JAMA Intern Med., 177(11), 1569-1575. https://doi.org/10.1001/jamainternmed.2017.3601

Price, C., McGinley, P., \& St John, A. (2020). Where Is the Value of Laboratory Medicine and How Do You Unlock It? The Journal of Applied Laboratory Medicine, 5(5), 1050-1060, https://doi.org/10.1093/jalm/jfaa116

Qehaja, A. B., Kutllovci, E., \& Pula, J. S. (2017). Strategic Management Tools and Techniques: A Comparative Analysis of Empirical Studies. Croatian Economic Survey, 19(1), 67-99. https://doi.org/10.15179/ces.19.1.3

Rovida, C., \& Hartung, T. (2009). Re-evaluation of animal numbers and costs for in vivo tests to accomplish REACH legislation requirements for chemicals - a report by the Transatlantic Think Tank for Toxicology (t4). ALTEX - Alternatives to animal experimentation, 26(3), 187-208. https://doi.org/10.14573/altex.2009.3.187

Shields, M., \& Young, S. M. (1994). Managing innovation costs: A study of cost conscious behavior by R\&D professionals. Journal of Management Accounting Research, 6(1), 175-196.

Simoens, S., Jacobs, I., Popovian, R., Isakov, L., \& Shane, L. G. (2017). Assessing the Value of Biosimilars: A Review of the Role of Budget Impact Analysis. Pharmacoeconomics, 35(10), 1047-1062. https://doi.org/10.1007/s40273-017-0529-x

Tetrevova, L. (2004). The role of bonds in the process of ownership restructuring of firms. Ekonomicky casopis, 52(6), 669-683. 